\title{
THE UN COVENANTS AND THE HuMAN RigHTS COMMITTEE
}

\author{
Don MacKay*
}

The second speaker at the April Seminar commemorating the UNDR was Don MacKay. In his paper he considers the international human rights developments since 1948, and the role in human rights implementation of the Human Rights Committee of the United Nations.

Dr Colin Aikman has focussed on the origins of the Universal Declaration on Human Rights, the foundation upon which the international human rights structure is built. My task is to talk about two other essential pillars of that structure, which he has mentioned the Covenant on Civil and Political Rights, and the Covenant on Economic, Social and Cultural Rights. Together with the Universal Declaration, the Covenants comprise what is known as the International Bill of Human Rights. I will also talk about the Human Rights Committee, which has an important role under the Covenant on Civil and Political Rights and under the Optional Protocol to that Covenant.

The two Covenants were concluded in 1966. Each deals with distinct areas. The Covenant on Civil and Political Rights, as its title implies, sets out a range of rights and freedoms which safeguard participation in civil and political life. These rights include the right of self determination, the right to life, liberty and security of the person, the right of equality under the law, and the right to take part in public affairs. Freedoms guaranteed by the Covenant include freedom of movement, thought and opinion, freedom of association and freedom from arbitrary arrest or detention. These are to be enjoyed by all individuals without distinction of any kind.

The Covenant on Economic, Social and Cultural Rights is designed to ensure the protection of people as full persons, through the pursuit of economic, social and cultural activities and development. This Covenant includes the right to work, to an adequate standard of living, to the highest attainable standard of physical and mental health, and to education and culture.

Deputy Secretary of the New Zealand Ministry of Foreign Affairs and Trade. Address to the New Zealand Institute of International Affairs Seminar commemorating the 50th Anniversary of the Universal Declaration of Human Rights. 
These rights differ from those set out in the Covenant on Civil and Political Rights in that they are progressive rather than absolute. Whereas the Covenant on Civil and Political Rights imposes an obligation on states to extend its rights and freedoms to all individuals in their territory, the Covenant on Economic, Social and Cultural Rights imposes an obligation on states to take steps with a view to achieving progressively the full realisation of the rights recognised in the Covenant, to the maximum of their available resources.

There is also a quite fundamental difference between the two Covenants and the Universal Declaration. The Universal Declaration is just that - it is a statement (albeit of the most solemn kind) by countries - and is not legally binding. The two Covenants are legally binding on states which are parties to them, and they are backed up by a system of monitoring and reporting on their implementation.

All States party to each Covenant must report periodically on the measures they have adopted to give effect to the rights in each Covenant and on the progress in individuals' enjoyment of those rights. States parties are required to submit an initial report on compliance within a certain period after they have become party (in the case of the Civil and Political Rights this is one year, for the Covenant on Economic, Social and Cultural Rights it is two) and thereafter every five years. Reports are submitted, respectively, to the Human Rights Committee, and to the Committee on Economic, Social and Cultural Rights.

In fact, of the eight treaty-based organs of the United Nations tasked with monitoring states' compliance under international human rights treaties, five operate in this way. With nearly 150 states party to each of the two Covenants, both undoubtedly give considerable substance to the implementation of international human rights across the globe, and also to the rights more generally set out in the Universal Declaration.

As well as the periodic reporting requirement, the Covenant on Civil and Political Rights has other weapons in its compliance armoury. There is, for example, an inter-state communications process. A state party may submit a communication to the Committee alleging that another state party is not fulfilling its obligations under the Covenant. The utility of this process is limited, however, by the requirement that both of the states parties concerned must have already declared that they recognise the competence of the Committee to receive and consider such communications. Only 44 states, including New Zealand, have made such declarations. So far this inter-state communications procedure has not been used.

By contrast, very heavily used - and much more important - is the right of individuals to submit communications to the Human Rights Committee, when they believe that their 
rights under the Covenant on Civil and Political Rights have been violated and they have been unable to obtain a remedy domestically.

The Convention on the Elimination of Racial Discrimination was the first to create such a right of individual petition, over thirty years ago. In 1950, when the Human Rights Commission was requested to come up with a similar right of individual petition under the Covenant on Civil and Political Rights, states were divided as to both its legality and utility. Compromise was reached in the form of an Optional Protocol, some two decades after discussion and debate on an International Bill of Human Rights had begun.

In fact, three treaty-bodies currently have the capacity to receive and deal with individual communications. As well as the two I have mentioned - the Human Rights Committee in respect of the Covenant on Civil and Political Rights, and the Committee on the Elimination of Racial Discrimination in respect of that Convention - the Committee on Torture can receive them under the Convention Against Torture. Discussions are underway on the creation of individual communications processes in respect of a further two treaties; the Convention on the Elimination of All Forms of Discrimination Against Women, and the International Covenant on Economic, Social and Cultural Rights.

New Zealand ratified both Covenants in 1978, and acceded to the Optional Protocol in 1989. So far, approximately two-thirds of the states party to the Covenant on Civil and Political Rights have also accepted the individual communications process established by the Optional Protocol.

There are, however, concerns about the way in which the compliance mechanisms are operating in practice.

In the first place there have been difficulties regarding the system of periodic reporting. The Alston Report on the Effective Functioning of Bodies Established Pursuant to United Nations Human Rights Instruments ${ }^{1}$ has pointed to considerable delays in the Committee's consideration of periodic reports, and a worrying failure on the part of some states to meet their reporting requirements. With regard to delays in considering reports, the Alston Report attributes these to the increasing number of ratifications of human rights treaties and the expansion of the human rights treaty system, combined with increasing budgetary pressures. Delays experienced by states parties between the submission and examination of their periodic reports has increased to the point where some states will wait almost three years before their reports are examined.

1 The Alston Report was transmitted under a note of the UN Secretary-General of 27 march 1997: UN Doc E/CN4/1997/74. 
On the question of states' adherence to the periodic reporting regime - and its effectiveness in monitoring compliance with the treaties - as at February 1998 1,134 reports are overdue. More than two-thirds of all states parties are in arrears with some or all of their reports.

The statistics are revealing. The worst offender in respect of its failure to submit reports is Guyana, which has 20 reports outstanding across the six human rights treaties. Ten of these are reports required by the Convention on the Elimination of Racial Discrimination. In second place, owing 18 reports, is Guinea.

In total, 421 reports are owed under Convention on the Elimination of Racial Discrimination, and 206 under the Convention on the Elimination of All Forms of Discrimination Against Women. Under the Covenant on Civil and Political Rights 138 reports are overdue, with countries such as the Central African Republic, the Democratic People's Republic of Korea, the Democratic Republic of the Congo, The Gambia, Guyana, Kenya, Mali, Suriname and the Syrian Arab Republic all owing three successive reports to the Committee.

In the event that the international community's stated goal of universal ratification of the human rights treaties was ever reached, or if all states actually reported as required, we might well find the Human Rights Committee and other similar bodies collapsing under the strain. In fact, the Alston Report estimated that if every state party with a report overdue under either of the Covenants were to submit that report tomorrow, the last to be received could not be considered, on the basis of existing arrangements, before the year 2003. By which time of course there would be a further backlog of subsequent reports.

As pointed out in the Alston Report, such large-scale non-reporting undermines the reporting system as a whole and can lead to a situation in which many states are effectively rewarded for violating their obligations while others are penalised for complying.

Let me now turn to the system of individual communications (or complaints) under the Optional Protocol to the Covenant on Civil and Political Rights. Again, it may be asked whether this is operating in quite the way that the original proponents of the system envisaged. At the outset, there is the question whether the system is actually hitting the right targets. By 1996, for example, 694 complaints had been received by the Human Rights Committee against 51 countries. Amongst the top five countries against which most complaints were made, were Canada, France and the Netherlands. In a world which has recently witnessed genocide, and where torture, arbitrary executions, imprisonment, and disappearances are commonplace, we must ask whether Canada, 
France and the Netherlands are really at the cutting edge of international human rights violations?

Looking at experience closer to home, in the ten years since New Zealand became party to the Optional Protocol, eight complaints against this country have been received by the Committee. Three were found by the Committee to be inadmissible, one communication has been withdrawn by the author, and four of them are still live.

Still awaiting final consideration by the Committee are, first, a complaint concerning the compulsory mental health detention and treatment of an individual; second, a group complaint relating to the enactment of the Citizenship (Western Samoa) Act 1982; third, a complaint which alleges breaches of several rights in relation to the prosecution, appeal and eventual periodic detention of an individual for certain offences. Fourth, and one of the most potentially far-reaching complaints still before the Committee, is a group complaint alleging that the 1992 Sealords Fisheries Settlement breached a number of the provisions of the Covenant on Civil and Political Rights.

Of the three communications rejected by the Committee as inadmissible, the determining factor in all three findings was a failure to substantiate the claim. Two of these claims concerned allegations of discriminatory legislation, one in relation to social security legislation and one in relation to the War Pensions Act 1954. The third complaint rejected as inadmissible, was from a prison inmate convicted in connection with Centrepoint offences and alleged, amongst other things, ill-treatment while in prison, including denial of adequate dental treatment, refusal to provide vitamin supplements and denial of proper reading glasses.

Some general trends may be perceived with regard to the individual communication procedure. One is that there appears to be an increasing use of the individual communication procedure to take up group complaints - that is, instances where the Covenant is alleged to have been breached through the treatment of a particular group. Such complaints often involve key public policy or social issues of the day, with farreaching implications not only for individuals but also for states themselves. A graphic illustration of this is the Toonen complaint against Australia. In this case it was alleged that Tasmanian criminalisation of homosexuality breached the Covenant on Civil and Political Rights. The United Nations Human Rights Committee agreed with these claims. The outcome was that the legislation in question was repealed. It is unlikely that the Australian Government, when it became party to the Covenant, ever envisaged that the individual communication process would be used to such far-reaching effect.

As mentioned, two of the communications about New Zealand also involve groups rather than individuals, and they could have significant implications if the Committee came to the view that the New Zealand Government had breached any rights under the 
Convention, and the Government then decided to act on the Committee's view. There are also other possibilities in the wind, including a suggestion made publicly that the issue of women's under-representation in Parliament might be taken to the Human Rights Committee if the outcome of domestic legal remedies is negative.

It is probably inevitable that many of the communications regarding Western democracies will involve group issues, and broader matters of public and social policy. There are, after all, far-reaching and effective systems in place domestically in these countries to deal with situations in which the rights of a specific individual have been violated.

It does mean, however, that the Human Rights Committee, in considering "individual" communications, can find itself dealing with huge policy issues in areas in which it has no background or expertise. It also means that findings of the Committee can have immense significance, going well beyond the rights of a particular individual.

This is coupled with an apparent tendency on the part of the Committee to broaden its scope. The Committee has recently indicated a disposition to take up issues which it had previously said were outside its jurisdiction. It has said that it does not regard itself as bound by its previous views on such matters. This can create real difficulties for states which, at the time of becoming party, have phrased reservations - or have decided not to enter reservations - on the basis of the Committee's previous jurisprudence, which it now says it can change.

The Committee may also be seeking to enhance the authority to be attached to the "views" it expresses on communications brought before it. While it has been well established that the Committee issues "views" not "decisions", and that its "views" are not binding on Governments, it has recently set up a new position of Special Rapporteur on Implementation. The Special Rapporteur has the responsibility of following up on states parties' implementation of the Committee's views which, along with some other recent developments, could be taken to imply that some judicial or quasi-judicial status should be attached to them.

Whether this is a good thing or a bad thing is obviously a matter for debate, and I do not propose embarking on that here. But it does raise another question, whether it is appropriate for an international body to have such a judicial or quasi-judicial role in cases which may have huge significance for states - more significance perhaps than some of the cases before the International Court of Justice or the WTO Disputes Settlement Body - if it does not have robust procedures and resources to match.

The Committee is made up of eighteen experts who meet for three weeks three times a year. During its meetings it deals with both periodic reports and individual communications. Nominees for membership of the Committee are not required to be 
lawyers, although electoral consideration is to be given to the usefulness of the participation of some persons having legal experience'. As a body of the United Nations, voting on candidates is inevitably subject to political considerations and extraneous influences such as vote-swapping for other bodies. Membership of the Committee is only part-time.

The ability of the Committee to consider communications and reports submitted to it is limited by the general resource constraints which exist within the United Nations system. The Alston report noted that the number of communications being processed under the various communications procedures has greatly increased and that existing backlogs are unacceptably high. It can now take up to 12 months for the Committee simply to respond to correspondence. The resources available to service the sizeable expansion in the United Nations human rights system have actually contracted rather than expanded, over recent years.

It should also be noted that individual communications are dealt with solely on the basis of written papers provided by the parties. There is no right of appearance. There is no hearing of evidence. Time constraints on the Committee have led to heavy reliance on the Secretariat, which has adopted a practice of providing summaries of communications to Committee members. This means that, normally, only a few members of the Committee will actually have read the communications from the parties before making a determination.

This may suggest a need for caution in any elevation of the Human Rights Committee as part of our quasi domestic legal structure, and the status to be accorded its views. The Committee should not be seen as a substitute for domestic processes, nor is it there to function as a final Court of Appeal in assessing whether a particular decision is right or wrong.

Speaking recently on the 50th anniversary of the Universal Declaration, Mary Robinson, United Nations High Commissioner for Human Rights, said that 'we cannot pretend that these achievements in the field of human rights have led to a significant decrease in the nature, gravity or number of human rights violations'. She describes the failure of human rights implementation as something which shames us all. Twice this decade we have witnessed genocide. Rape has been used as a systematic weapon of war, in defiance of human rights instruments and international humanitarian law. Torture, arbitrary executions and disappearances are still common. Hundreds of millions of people live in extreme poverty, suffering from malnutrition, disease and lack of hope. Millions of children die from lack of safe water or from preventable diseases. Millions more are subject to sexual abuse and commercial exploitation. There continues to be widespread discrimination on the basis of gender, ethnicity, religious belief or sexual orientation. 
I am much more positive. I think that the Universal Declaration, and the Covenants, and the Optional Protocol have had an important role to play in improving human rights internationally, and that they continue to do so. So, too, has the United Nations Human Rights Committee. The conclusion of other Conventions, and the creation of other bodies, including important new ones such as the International Criminal Court, also have a huge role to play.

I hope that we will soon see reforms to the international human rights system that will enable existing bodies, including the Human Rights Committee, to cope more effectively with the huge pressures upon them. The streamlining of periodic reporting, the harmonising of reporting phases, and allowing Committees to examine compliance even when a state does not submit a report, would all be worthwhile improvements. Perhaps we may even see some more resources brought to bear. But we do need to be realistic about the limitations upon the ability of the international system, and the Covenants, to deliver, particularly in our domestic context. And we must not lose sight of the real challenges to human rights that exist around the world. 